\title{
Kurşun, Civa, Kadmiyum: Çocuk Sağlığına Etkileri ve Temasın Belirlenmesinde Saç Örneklerinin Kullanımı
}

\section{Lead, Mercury, Cadmium: Effects on Child Health and Using Hair Samples in Determination of Exposure}

\author{
Emel ÖRÜN ${ }^{1 *}$, S. Songül YALÇIN ${ }^{2}$ \\ 1 Fatih Üniversitesi Hastanesi, Ankara \\ ${ }^{2}$ Hacettepe Üniversitesi Tıp Fakültesi, Sosyal Pediatri Ünitesi, Ankara
}

\begin{abstract}
Özet: Ağır metaller yaygın kullanımları nedeniyle en zararlı çevresel kirleticilerdendir. Kurşun, civa ve kadmiyum çevresel kaynakları, vücuda alınış yolları, toksik etkileri ve vücutta saptanma yöntemleri iyi bilinen metallerdir. Çocukluk döneminde ağır metal temasının saptanmasında saç materyalinin kullanılması, toplanması, saklanması ve taşınması kolay ve düşük maliyetlidir. Bununla birlikte saçın alınacă̆ yer ve miktarının net olmaması, kontaminasyon riski, güvenilir referans aralıklarının olmayışı dezavantajlarıdır. Günümüzde kan ve saç düzeyleri ile büyüyen fetusta etkileri arasında ilişki için yeterli verisi olan tek element metil civadır. Bununla birlikte kurşun ve kadmiyum temasının ve toksik etkilerinin değerlendirmesinde saç örneklerinin kullanılması sınırlıdır. Çevresel teması göstermede saç analizinin iyi bir yöntem haline gelmesi için birçok bilimsel konunun aydınlatılmaya ihtiyacı vardır.

Anahtar kelimeler: Kurşun, Civa, Kadmiyum, Saç Örneği, Çocuk.
\end{abstract}

\begin{abstract}
Heavy metals are the most harmful environmental pollutants, due to widespread use. Lead, mercury, and cadmium are well-known regard as environmental resources, ways of receiving the body, the toxic effects, detection methods in biological markers. Using hair sample have many advantages such as easily and noninvasively collected with minimal cost collection, and it is easily stored and transported to the laboratory for analysis. However, it have disadvantages risk of contamination, lack of reliable reference values, and no consensus exists on the length of the hair specimen to be collected, or the amount, or the position on scalp. Nowadays, methylmercury is the only element for which sufficient data exist to define the relationship between concentrations in blood, concentrations in hair, and effects on the target (the developing fetus). But, analysis of lead and cadmium in hair samples is limited to use for the exposure to lead and cadmium and their toxic effects. Many scientific issues need to be highlighted before hair analysis can become a useful tool in understanding environmental exposures.
\end{abstract}

Key words: Lead, Mercury, Cadmium, Hair sample, Child.

\section{Giriş}

Günümüzde artan nüfus, kentleşme ve endüstrileşme tüm canlıların ağır metal temasını artırmıştır (Järup, 2003, Wong ve Lye, 2008). Ağır metaller yaygın kullanımları nedeniyle en zararlı çevresel kirleticilerdendir. Kurşun $(\mathrm{Pb})$, civa (Hg) ve kadmiyum (Cd) Toksik Madde ve Hastalık Kayıt Ajans1 (Agency for Toxic Substances and Disease Registry: ATSDR)'nin en son 2007'de bildirdiği öncelikli tehlikeli maddeler içerisinde ilk 10'a aldığı toksik ağır metallerdir (ATSDR, 2007).

Yaşadığı çevrede ağır metal düzeyinin artması çoğu canlı dokusunda ağır metal düzeylerinin artmasına yol açmıştır (Dietz vd, 2009). Besin zincirinin en üstünde yer alan insan ve yavrusu giderek artan düzeylerde ağır metallerle temas etmektedir. Bu nedenle son 30 yıldır ağır metallerin toksik ve istenmeyen etkilerini inceleyen çalışmalara ağırlık verilmiştir. İnsanların toksik metallerle tanışması

\footnotetext{
* Iletişim: siyalcin@hacettepe.edu.tr
} 


\section{E. Örün ve S.S. Yalçın}

intrauterin dönemde başlar ve sonrasında başlıca anne sütü ve soludukları hava ile ağır metal teması sürer. Hızlı büyüme ve gelişim sürecinde olan fetus ve bebekler ağır metallerin toksik etkilerine karşı erişkinlerden daha hassastır (Järup, 2003, Wong ve Lye, 2008).

Günümüzde ağır metaller vücuttaki toksikokinetiğine göre tam kan (plazma, tam kan), tükürük, diş, tırnak, kemik, gaita, idrar, kord kanı ve anne sütü gibi birçok biyolojik materyalde analiz edilmektedir. Saçta toksik metal (kurşun, civa, kadmiyum, arsenik vs), ve mineral analizi (çinko, bakır, selenyum, krom, manganez, nikel vs.) adli tıpta, toplumun toksik metal temasının değerlendirilmesinde ve çevresel kirleticilerin monitorizasyonunda kullanılmaktadır. Saçtaki toksik metal düzeyi, saçın uzama sürecindeki temasını gösterir. Saç uzama süresi haftalar hatta birkaç ayı bulmaktadır (Barbosa vd, 2005). Metilciva temasının gösterilmesinde saç iyi bir materyal olarak kabul görmektedir (Berglund vd, 2005). Saçtaki $\mathrm{Pb}$ ve Cd konsantrasyonlarının vücut yükünü yansitıp yansıtmadığı ve diğer belirteçlerle korelasyonu konusunda sonuçlar çelişkilidir (Esteban ve Castaño, 2009).

Saç materyalinde birçok elementin saptanmasında kullanılan analitik metodlar arasında en yaygını atomic absorption spectrometry (AAS)'dir. Kurşun için en sı graphite furnace atomic absorption spectrometry (GF-AAS) kullanılmaktadır. Güvenilir toksikoloji laboratuvarlarında toksik metallerin tespitinde $\mathrm{Pb}$ ve $\mathrm{Cd}$ için $G F-A A S, \mathrm{Hg}$ için cold vapor-AAS yöntemi kullanılmaktadır. $G F$ $A A S$ metodu güvenilir kabul edilmekte ve analiz işlemi için 0.5 gram saç materyali kullanılmaktadır. Diğer metodlar Inductively coupled plasma-atomic emission spectrometry (ICP-AES), inductively coupled plasma mass spectrometry (ICP-MS)'dır. ICP-MS yöntemi ICP-AES'e göre daha sensitiftir. ICP-MS; GF-AAS'e göre daha maliyetlidir fakat tek bir örnekte birçok metal düzeyinin belirlenebilmesi, düşük saptama limitleri, güvenilirliği ve daha az saçta analiz yapılabilmesi $(0.25-1$ gram) avantajlarıdır (ATSDR, 2011).

Saç örneklerinin alınması ve ölçüm öncesi hazırlanması toksik metal düzeyine ait sonuçları önemli ölçüde etkilemektir. Kafa derisindeki saç foliküllerinin \%90’ı büyüme fazındadır ve uzama hızları mozaik pattern gösterir. Alınacak örneğin yüze yakın yerlerden olması önerilmez; çünkü sebaseöz (yağsı) sekresyonların ve yüz hijyeni için kullanılan temizlik ürünlerinin kontaminasyon riski bu bölgede yüksektir. Bu yüzden oksipital (ense) bölgeden makasla alınması önerilmektedir. Uzama hızlarının düşük olması ve çoğunun dinlenme fazında olması nedeniyle aksiller (koltuk altı) ve pubik kılların (genital bölge) kullanılmasını öneren laboratuvarlar da vardır. Bu bölgeden alınan kılların apokrin bezlerin salgısı, kişisel hijyen ürünleri ve giysilerden kaynaklan kontaminasyon riski bulunmaktadır. Ayrıca bu bölgeden yapılacak ölçümler için yayınlanmış referans aralıkları bulunmamaktadır. Saçlı deriden alınan materyalin dış ortam bulaşlarından arındırılması için kullanılan birçok yıkama metodu vardır (örn: nonpolar solvent-aseton, deiyodinize su, hafif iyonik deterjansodyum lauril sülfat). Ancak günümüzde saçta endojen depolanmış elementi etkilemeden, ekzojen kirleticileri uzaklaştıran kapasitede bir metod yoktur (ATSDR, 2011).

$\mathrm{Bu}$ makalede $\mathrm{Pb}, \mathrm{Hg}$ ve Cd'un çocuk sağlığı üzerine olumsuz etkileri, çocuklarda temasın belirlenmesinde saç örneklerinin kullanımdaki yeri ve en sık kullanılan biyolojik materyallerde saptanan düzeyle saç düzeyleri arasındaki ilişkiyi araştıran çalışmalara ait sonuçlar derlenmiştir.

\section{Kurşun (Pb)}

Doğada az miktarlarda ama her yerde bulunabilen, mavimsi-gümüş grisi renginde bir ağır metaldir. İnorganik ve organik olmak üzere iki formu bulunur. Organik Pb bileşiği, petrol yapısına eklenen formdur (WHO, 2001). Kurşunlu benzin kullanımı atmosfere salınan Pb'nun en önemli kaynağıdır.

Kurşun plasentadan kolaylıkla geçer ve çocukların $\mathrm{Pb}$ ile teması prenatal dönemde başlar. Fetusa geçen $\mathrm{Pb}$ miktarı anneye ait vücut $\mathrm{Pb}$ yükü ile ilişkilidir. Gebelik sırasında anne kemiğindeki 
$\mathrm{Pb}$ mobilize olur ve plasenta aracılı̆̆ ile fetusa geçer. Devam eden çocukluk dönemlerinde en önemli $\mathrm{Pb}$ teması $\mathrm{Pb}$ ile kontamine boya tozu, kırıntısı, toprak, su ve yabancı cisimleri ağız yoluyla alması ile olmaktadır (Markowitz, 2007). Kurșun özellikle gelișen beyin üzerine toksiktir. Çocuklarda uzun süreli düşük dozlarda $\mathrm{Pb}$ teması entellektüel kapasitede azalmaya yol açar; Kan $\mathrm{Pb}$ düzeyinde 10 $\mu \mathrm{g} / \mathrm{dl}$ 'lik artış IQ'da 2 puanlık düşmeye yol açar (WHO, 2006). İntrauterin dönemde $\mathrm{Pb}$ teması olan bebeklerde erken doğum ve intrauterin büyüme geriliği görülmüştür (Triche ve Hossain, 2007; Atabek vd, 2007).

Şimdiye kadar $\mathrm{Pb}$ temasını göstermek, takip etmek, gerekli durumlarda tedavi şeklini belirlemek, birincil koruyucu önlemleri almak amaciyla birçok biyolojik örnekte $\mathrm{Pb}$ ölçümü yapılmıştır. En sık kullanılan ve en güvenilir kabul edilen tam kanda $\mathrm{Pb}$ düzeyidir (Barbosa vd, 2005). Kan kurşun düzeyi (KKD) ölçümü tarama, tanı ve uzun dönemde biyomonitörizasyon amaciyla kullanılmaktadır. Ölçülen KKD hem şimdiki temasın hem de kemikten kana geri $\mathrm{Pb}$ geçişin bir sonucu olarak geçmiş temasın göstergesidir. Ayrıca bir kez ölçülen KKD ile Pb temasının kısa süreli yüksek miktarda veya uzun süreli düşük miktarda olup olmadığının ayrımını yapmak mümkün değildir. KKD düzeyinin, Pb'la temasın boyutunu ve şeklini göstermesinde sıkıntılar yaşanması başka biyolojik örneklerin arayışını gündeme getirmiştir. Bu amaçla plazma/serum, tükrük, diş, kemik, gaita, idrar, saç, tırnak, beyin omurilik sıvısı, kord kanı ve anne sütü örnekleri $\mathrm{Pb}$ temasının araştırılmasında kullanılmıştır (Robinowitz vd, 1985; Hu vd, 1998; Schütz vd, 1996; Omokhodion ve Crockford 1991; Schuhmacher vd, 1991; Takagi vd, 1988; Butler vd, 2006; ).

Kurşun temasını göstermede saçın biyolojik örnek olarak kullanılması sınırlıdır (WHO, 2006). Saçın toplanması, saklanması ve taşınması kolay ve düşük maliyetlidir. Bunun birlikte çalışmalarda saç örneği alınırken dikkat edilecek noktaların netleşmemesi (alınacağı yer, miktar), kontaminasyon riski, güvenilir referans aralıklarının olmayışı sıkıntı yaratmaktadır. Saç $\mathrm{Pb}$ düzeyi yaş, cinsiyet, saç rengi, saça uygulanan işlemler (ağartma, boyama, perma), sigara içme, ekolojik faktörlerden (mevsim, coğrafik, 1rk/etnik) etkilenmektedir (Barbosa vd, 2005).

Hayvan deneylerinde temas boyunca doz bağımlı saç ve kan $\mathrm{Pb}$ düzeylerinde artma olduğu gösterilmiştir. Mesleki ve çevresel teması olan vakalarda kan ve saç $\mathrm{Pb}$ düzeyi arasında ilişki olduğu bildirilmiştir (Esteban ve Castaño, 2009). Nowak ve ark. Polonya'da metal teması farklı iki bölgede yaptıkları çalışmada $\mathrm{Pb}$ düzeylerini saç, tırnak ve diş örneklerinde ölçmüşlerdir. Bölgeler arasında saç $\mathrm{Pb}$ düzeyini istatistiksel olarak farklı bulmuşlar ve saçtaki $\mathrm{Pb}$ düzeyinin iyi bir gösterge olabileceğini ileri sürmüşlerdir (Nowak ve Chmielnicka, 2000). CDC (Centers for Disease Control) 189 çocukta Pb toksistesini belirlerken kan ve saç $\mathrm{Pb}$ düzeylerini karşılaştırmışlardır. (ortalama kan $\mathrm{Pb}$ düzeyi: 9.8 $\mu \mathrm{g} / \mathrm{dL}$; ortalama saç $\mathrm{Pb}$ düzeyi: $7.2 \mu \mathrm{g} / \mathrm{g}$ ). Bir tarama metodu olarak saç $\mathrm{Pb}$ ölçümünün sensitivitesi $\% 57$, yalancı negatiflik oranı: \%18 bulunmuștur. Özellikle düşük kan $\mathrm{Pb}$ düzeylerinde $(<12 \mu \mathrm{g} / \mathrm{dL})$ saç $\mathrm{Pb}$ düzeyinin kan $\mathrm{Pb}$ düzeyini öngörme gücü düşük bulunmuştur. Araştırmacılar çocuklarda $\mathrm{Pb}$ toksisitesinin taranmasında saç $\mathrm{Pb}$ ölçümünün yeterli bir metot olmadığı sonucuna varmışlardır (Esteban vd; 1999). Buna karş1lık döküm işinde çalışmış ve ölmüş işçilerin saç $\mathrm{Pb}$ düzeyleri ile karaciğer ve böbrek dokularında ölçülen Pb miktarı arasında korelasyon saptanmıştır (Gerhardsson vd. 1995).

Dünya genelinde şimdiye kadar yapılmış çalışmalarda saç $\mathrm{Pb}$ düzeyi geniş bir aralıkta dağılmaktadır (1.11-48.7 $\mu \mathrm{g} / \mathrm{g})$. Türkiye'de Özden ve ark. 1998-2000 yılları arasında 1 ay-2 yaş arasındaki çocuklarda yaptıkları çalışmada saç Pb düzeyini 1 aylık 119 bebekte $2.0 \pm 1.6 \mu \mathrm{g} / \mathrm{g}, 6$ aylık 193 bebekte $3.4 \pm 3.0 \mu \mathrm{g} / \mathrm{g}, 12$ aylık 185 bebekte $4.3 \pm 3.8 \mu \mathrm{g} / \mathrm{g}, 24$ aylık 131 bebekte $5.3 \pm 3.4 \mu \mathrm{g} / \mathrm{g}$ saptamışlardır. Bu çalışmada yaşla beraber saç Pb düzeylerinin arttığı görülmüştür (Özden vd, 2003). Yüksek saç $\mathrm{Pb}$ düzeyleri bitkisel çay verme, sigara dumanı teması, kaloriferli evde yaşama ile ilişkili bulunmuştur. Özden ve ark.'nın 11-13 yaş arası okul çocuklarında yaptığı başka bir çalışmada evde sigara içen kişi sayısı arttıkça daha yüksek saç Pb düzeyi saptamışlardır (Özden vd, 2007). Mortada ve ark. (2004) Mısır'da 25-35 yaş arası sigara içen ve içmeyenlerin kan ve saç $\mathrm{Pb}$ düzeylerini karşılaştırdığında sigara içenlerde saç ve kan $\mathrm{Pb}$ düzeyini anlamlı düzeyde yüksek bulmuşlardır. 


\section{E. Örün ve S.S. Yalçın}

Souad ve ark. (2006) 0-12 ay arasındaki 573 bebekte saç $\mathrm{Pb}$ düzeyinin yaşla arttığını ve yüksek saç $\mathrm{Pb}$ düzeyinin, kız cinsiyet, şehir merkezinin yakınında yaşama ve annenin az eğitimli olması ile ilişkili bulmuşlardır. Barton (2011) yaptığı okul öncesi dönemdeki 300 çocuğun süt dişi, saç ve kan örneklerinde yürüttüğü çalışmasında; saç ve kan $\mathrm{Pb}$ düzeyleri arasında pozitif bir ilişki, saç $\mathrm{Pb}$ düzeyi ile $\mathrm{Cd}$ arasında pozitif ilişki, saç $\mathrm{Pb}$ ile çinko arasında negatif bir ilişki saptamıştır. Saç $\mathrm{Pb}$ düzeylerinin $\mathrm{Cd}$ ve $\mathrm{Zn}$ düzeyleri ile birlikte değerlendirilmesi gerektiği sonucuna varmıştır. Aynı zamanda bazı hastalık ve semptomlarla saç $\mathrm{Pb}$ düzeyi arasında ilişki gösterilmiş̧ir. Sigara içen ve içmeyen romatoid artritli erişkin hastalarda saç $\mathrm{Pb}$ düzeyi, kontrol grubuna göre daha yüksek bulunmuştur $\mathrm{Pb}$ gibi toksik elementlerin vücut yükünün fazla olmasının eser element metabolizmasını (çinko, bakır, selenyum) bozarak hastalık patogenezinde ve seyrinde rolü olabileceği ileri sürülmüştür (Afridi vd, 2011).

Kurşunun çocuk sağllğ için önemli bir yer tutmasının nedeni çocuklarda gelişimsel problemlere yol açan nörotoksik bir metal olmasıdır. Bonithon-Kopp ve ark. 26 yenidoğandan aldıkları saç örneklerinde $\mathrm{Pb}$ düzeyi yüksek olan vakaları 6 yaşında McCarthy Ölçeği ile (McCarthy Scales of Children's Abilities) değerlendirdiğinde bu vakaların motor ve algısal yeteneklerinin olumsuz etkilendiğini bildirmiştir (Bonithon-Kopp vd, 1986).

\section{Civa (Hg)}

İnsanlar üç değişik civa formuyla temas edebilir; elemental civa, inorganik civa ve organik civa (Clarkson, 1998). İnsanların inorganik civa temasında en önemli kaynak amalgam diş dolgusudur (Davidson vd, 2004). Metil civa temasında civa ile kirlenmiş sularda yaşayan büyük balıklar en önemli kaynaktır. (WHO, 2000). Organik Hg bileşikleri yağda çözünür, organik yapısı ve kısa hidrokarbon zinciri olması nedeniyle kolayca gastrointestinal sistemden emilir. Metilciva kan-beyin bariyerinden, plasentadan ve süt kanallarından geçer. Metilciva esas olarak gaita ile vücuttan atılır. Metilcivanın önemli bir kısmı bağırsaklarda demetilasyona uğrayarak inorganik civa formunda atılır.

Civa doğada geniş şekilde dağıldığı için temas öyküsü olmasa da birçok insanın idrar ve kanında Hg saptanabilir ( $\mathrm{Ng}$ vd, 2007). Metil Hg'nın hemoglobine bağlanma özelliğinden dolayı vücuttaki Hg miktarını ölçmede en spesifik gösterge eritrosit Hg konsantrasyonudur, fakat ölçümü çok zordur (Sakamoto vd, 2002). Günümüzde en sık kullanılan ve geçerlilik çalışmaları yapılmış olan idrar ve kan düzeylerinin ölçümüdür. Kan $\mathrm{Hg}$ düzeyi hem metil $\mathrm{Hg}$ hem inorganik $\mathrm{Hg}$ miktarını yansıtır. Bir kişinin $\mathrm{Hg}$ temasının gösterilmesinde kan ve idrar (24 saatlik) düzeylerinin birlikte değerlendirilmesi önerilmektedir ( $\mathrm{Ng} \mathrm{vd,} \mathrm{2007).}$

Kan Hg düzeyi kısa dönem teması (100-140 gün) göstermektedir. Saç Hg düzeyi ise geçmiş döneme ait teması (bir saç segmentinin uzama süreci $1 \mathrm{~cm} /$ ay) gösterir. Civa kan $\mathrm{Hg}$ düzeyi ile orantılı olarak saçın keratinizasyon aşamasında sülfür içeren aminoasitlere bağlanarak saç içine girer. Saçtaki total Hg'nın \%70-80'i MeHg'dır (Cox vd, 1989). Saç Hg düzeyi metil civa temasının belirlenmesinde iyi bir biyolojik örnek olarak kabul edilmektedir. Saç örneği almada ve analizinde kullanılacak yöntemlerin standardize edilmemiş olması, aynı kişide farklı çıkması, dış ortamdan Hg'ın saça bulaşma riski gibi sorunlar yaşanmaktadır. Bu nedenle protokollerin standardizasyonu ve referans aralığının belirlenmesi için daha fazla çalışmaya ihtiyaç vardır. Yapılan bir metaanaliz çalışmasında kord kanı, kan ve saç $\mathrm{Hg}$ düzeyleri arasında korelasyon olduğu fakat idrar düzeyleri ile korele olmadığ1 gösterilmiştir ( $\mathrm{Ng}$ vd, 2007). Kan ve saç düzeyindeki korelasyon varlığına rağmen, klinik karar verme aşamasında saç düzeyinin kan ve idrar $\mathrm{Hg}$ ölçümlerinin yerini alması için yeterli görülmemektedir.

Amerikan Çevre Koruma Ajansı bir yaşına kadar bebek saçı $\mathrm{Hg}$ düzeyi için güvenli düzeyi $<1$ $\mu \mathrm{g} / \mathrm{g}$ olarak bildirmiştir (U.S. EPA, 2005). Şimdiye kadar yapılan dünya genelinde çalışmalarında bebek saç Hg düzeyi $0.22-2.40 \mu \mathrm{g} / \mathrm{g}$ aralığında tespit edilmiştir. Diez ve ark.'nın İspanya'nın 4 ayrı bölgesinde yaşayan yenidoğan (n:82) ve okul öncesi çocuklarda (n:136) yaptıkları çalışmada okul 
öncesi grupta kızlarda saç total $\mathrm{Hg}$ düzeyini daha yüksek bulmakla beraber (1.06 ve $0.78 \mu \mathrm{g} / \mathrm{g}$ ) bu fark istatistiksel olarak anlamlı bulunmamıştır. Yenidoğan grubunda ise cinsiyet, doğum haftası, anne yaşı, eğitim durumu, sosyal statü ve paritenin saç $\mathrm{Hg}$ düzeyini etkilemediği görülmüştür (Díez vd, 2009). Anne saçı Hg düzeyi, anne kanı ve kord kanı ile ilişkisinden dolayı fetusun intrauterin $\mathrm{Hg}$ temasını gösteren bir belirteçtir. Grandjean ve ark. gebeliği boyunca balina eti yiyen annelerin saç Hg düzeyi ile kord kanı $\mathrm{Hg}$ düzeyi arasında pozitif korelasyon bulmuşlardır. Yüksek kord kanı ve anne saçı $\mathrm{Hg}$ düzeyleri artmış balık eti tüketimi (özellikle balina), ileri anne yaşı, doğum sayısının fazlalılığı ile ilişkili bulunmuştur (Grandjean vd, 1992).

İnorganik civadan ziyade metilciva çocuk sağlığını daha olumsuz etkilemektedir (WHO, 2007). Yüksek dozlarda metilcivayla temas serebral palsi benzeri tabloya yol açarken, düşük dozlarda nörogelişimsel geriliklere, öğrenme ve hafiza problemlerine yol açmaktadır (Amin-Zaki vd, 1979; Davidson vd, 2004; Steuerwald vd, 2000). Hayatın erken döneminde (intrauterin ve postpartum) $\mathrm{Hg}$ teması ile nörogelişimsel bozukluklar arasındaki ilişkiyi inceleyen birçok çalışma vardır. Irak’ta $\mathrm{MeHg}$ ile kontamine tahıldan yapılmış ekmeği tüketen grupta MeHg teması olan çocukların 30 aylık olduğunda gelişim basamakları değerlendirilmiştir. Anne saç $\mathrm{Hg}$ düzeyi 10-20 $\mu \mathrm{g} / \mathrm{g}$ olan çocuklarda gelişim basamaklarının geciktiği ve ve doz-cevap ilişkisi olduğu bildirilmiştir. Fakat çalışmanın iyi planlanmış olmaması, çocukların doğum tarihlerinin tam olarak bilinmemesi, nörolojik bulgusu olan vaka sayısının az olması gibi sınırlılıklarına dikkat çekilmiştir (Davidson, 2004). Grandjean ve ark. Faroe Adaları'nda doğumdan sonra ilk bir yıl takip ettikleri 583 bebeğin ve annesinin saç Hg düzeyini ölçmüşlerdir. 5-12. aylarda bebeklerin oturma, emekleme ve ayakta durma becerileri izlenmiştir. Sözkonusu becerileri geç kazanan bebeklerin 12. ay saç $\mathrm{Hg}$ düzeyleri yüksek bulunmuştur. Bununla birlikte becerileri gerçekleştirme ile doğumdaki anne saçı ve kord kanı Hg düzeyi arasında bir ilişki gösterilememiştir (Grandjean vd, 1997). Marques ve ark.'nın (2007) Brezilya'da 100 anne-bebek çiftini doğumda ve laktasyonun 6. ayında bebek saçı ile anne saçı Hg düzeyi ilişkili bulunmuştur. Gesell Gelişim Skalası 6.ayda bebeklerin \% 26'sinde gelişme geriliği saptamıştır. Sadece altı bebekte birçok alanda (dil, adaptasyon vs) gerilik saptanmıştır. Birçok alanda geriliği olan bebeklerin anne eğitim ve gelir düzeyinin düşük olmasının karıştırıcı bir faktör olabileceği belirtilmiştir. Chevrier ve ark. (2009) 7-12 yaşlarında 395 Amazonlu çocuğun $\mathrm{MeHg}$ temasın göstergesi olan saç $\mathrm{Hg}$ düzeyini ölçmüşlerdir (saç Hg düzeyi aralığı: 0.5-63.9 $\mu \mathrm{g} / \mathrm{g}$ ). Metilciva ile temas eden çocukların nörogelişim düzeylerini değerlendirmek için Stanford-Binet Kopyalama Testi uygulamışlardır. Saç Hg düzeyi > 10 $\mu \mathrm{g} / \mathrm{g}$ olan çocuklarda verileni çizme alanında (drawing task) aldıkları skorlar, saç $\mathrm{Hg}$ düzeyi $<10 \mu \mathrm{g} / \mathrm{g}$ olan çocuklara göre 1.2 puan daha düşük bulunmuştur.

Cox ve ark. anne saçındaki $\mathrm{Hg}$ düzeyinin 10-20 $\mu \mathrm{g} / \mathrm{g}$ üzerine olması durumunda $\% 5,70$ $\mu \mathrm{g} / \mathrm{g}$ 'nin üzerinde ise \%30 oranında bebeğin nörolojik bozukluk açısından risk taşıdığını bildirmiştir (Cox vd, 1989). Holmes ve ark. ise otizmli çocukların saç $\mathrm{Hg}$ düzeylerini normal çocuklara göre düşük bulmuşlardır ve bu sonucun otizmli çocuklarda saçtan Hg'nın ekskresyonunun bozulmasına bağlı olabileceğini ileri sürmüşlerdir (Holmes vd, 2003).

\section{Kadmiyum (Cd)}

Kadmiyum batarya yapımında, reaktör kontrol çubuklarının üretiminde, boya ve plastik yapımında, metal kaplama işlemlerinde kullanılmaktadır (ATSDR, 2008). Havadaki Cd tozlarının atmosferde birikmesi, Cd içeren gübrelerin kullanılması ve tarım alanlarının sulanmasında lağım sularının kullanılması insanların tüketeceği ürünlerin kontaminasyonuna yol açarak $\mathrm{Cd}$ alımının artmasına yol açabilir (Järup ve Akesson, 2009). Özellikle Cd ile kontamine toprakta yetişen lifli yeşillikler, patates, havuç, kereviz gibi köklü sebzeler, pirinç, buğday gibi tahıllarda, yağlı tohumlarda yüksek konsantrasyonda bulunur. Ayrıca kabuklu deniz hayvanlarında (istridye, yengeç), yumuşakçalarda, hayvan sakatatlarında (özellikle yaşlı hayvanların karaciğer ve böbreklerinde), yabani mantarlarda $\mathrm{Cd}$ düzeyi yüksektir. Ayrıca sigara dumanında $\mathrm{Cd}$ bulunur ve içicilerin vücutlarına 


\section{E. Örün ve S.S. Yalçın}

bir paketle 1-2 $\mu \mathrm{g}$ Cd girmektedir. Diyette kalsiyum, protein, çinko, demir ve bakırın az olması bağırsaktan Cd emilimini arttırmaktadır (Patrick, 2003).

Günümüzde kullanılan biyolojik örnekler arasında idrar, kan, saç, tırnak ve anne sütü yer almaktadır. İdrardaki Cd konsantrasyonu böbrek Cd düzeyi ile orantılıdır. Kan ve idrar Cd düzeyleri arasında yüksek derecede ilişki vardır. Cd vücut yükünün tahmininde her iki biyolojik materyalinde kullanışlı olduğu düşünülmektedir (Omarova ve Philips, 2007). Kan Cd düzeyi son 3-4 aydaki Cd temasının en iyi göstergedir. Kadmiyumun neden olduğu renal tubuler disfonksiyonun erken belirtisi düşük molekül ağırlıklı proteinlerin ( $\beta 2$-mikroglobuin, $\alpha 1$-mikroglobulin, retinol bağlayan protein) atılımının artmasıdır (Järup ve Akesson, 2009). Bu nedenle idrarda bu proteinlerin ölçümü kronik temasın göstergesi olarak kullanılmaktadır (Mortada vd, 2004).

Saç Cd ölçümü dış ortamdan Cd bulaşı riski taşımaktadır (ATSDR, 2008). Dış ortamdan Cd bulaşının mesleki teması olan kişiler için daha önemli olabileceği düşünülmektedir. Bununla birlikte anne saçı ve yenidoğan bebek saçı arasında ve baş saçı ile pubik bölgeden alınan kıldaki Cd düzeyi arasında pozitif korelasyon gösterilmiştir (Huel vd, 1984, Wilhelm vd, 1990). Ekzojen Cd kontaminasyonu riskinin az olması nedeniyle yenidoğan bebek saçında Cd ölçümü daha güvenilirdir. Dışarıdan bulaşı azaltmak için saçlı deriden ilk $8 \mathrm{~cm}$ 'lik saç kısmının alınması ve uygun yıkama tekniklerinin kullanılması önerilmektedir (ATSDR, 2008).

Basılı yayınlarda ortalama bebek saçı Cd düzeyi $0.22-0.94 \mu \mathrm{g} / \mathrm{g}$ aralığında bildirilmektedir. $\mathrm{Cd}$ temasında en önemli risk faktörü sigara temasıdır. Özden ve ark. (2007) okulu ana caddeye yakın olan ve kaloriferli evde yaşayan çocuklarda saç Cd düzeyini yüksek bulmuşlardır. Ayrıca evde sigara içenlerin sayısı arttıkça saç Cd düzeyini saptama oranının arttığını bildirmişlerdir. Serdar ve ark. (2012) 1-6 yaş arası 95 çocuğun saç örneklerinde anne ve/veya babası sigara içen çocukların $\mathrm{Cd}$ düzeylerini istatistiksel olarak anlamlı düzeyde yüksek bulmuştur. Razi ve ark. (2012) tekrarlayan hışıltısı olan bir grup çocukta atak sıklığı ile saç Cd düzeyleri arasında pozitif bir ilişki (çevresel sigara teması değişkeni kontrol edilerek) olduğunu bildirmişlerdir. Bununla birlikte Alman Ulusal Çevre araştırmasında saç $\mathrm{Cd}$ düzeyinin kan ve üriner Cd konsantrasyonunun en önemli belirleyicisi olmasına rağmen, aktif sigara içiciliği ile ilişkisi zayıf bulunmuştır. Dış ortam aktiviteleri, mevsim ve içme suyundaki Cd miktarının saç Cd düzeyini belirleyen önemli ekzojen kaynak olduğu vurgulanmıştır (Seifert vd, 2000).

Kadmiyum böbrek, akciğer ve gastrointestinal sistemi etkileyebilmektedir. Uzun süreli düşük dozlarda Cd teması kemik kaybına yol açmaktadır. Prenatal dönemde $\mathrm{Cd}$ teması olan hayvanlarda düşük doğum ağıllığı, iskelet anomallikleri, davranış ve öğrenme problemleri gözlenmiştir (Ali vd, 1986; Baranski, 1985; Petering vd, 1979). Hayvan deneylerinde gebelik döneminde Cd temasının en çok sinir sistemini etkilediği gözlenmiştir (Ali vd, 1986). Cd'un insan üzerindeki nörotoksik etkileri üzerine az sayıda çalışma bulunmaktadır. Birkaç çalışmada çocuklarda saç Cd düzeyi ile zeka puanı arasında ters bir ilişki olduğu gösterilmiştir (Viaene vd, 2000; Thatcher vd, 1882; Stellern vd, 1983).

\section{Sonuç}

Sonuç olarak çocuklarda saç örneklerinde $\mathrm{Pb}, \mathrm{Hg}$ ve $\mathrm{Cd}$ varlığı ile toksik etkileri ve bazı risk faktörleri arasında ilişki gösterilmiştir. Bununla birlikte metil civa dışında saçta kurşun ve kadmiyum düzeyi için güvenilir, emniyetli kabul edilen düzey henüz bilinmemektedir. Gelecekte bu alanda yapılacak çalışmaların örnek alma, örnek hazırlama ve ölçüm standartlarının oluşturulması ve insan sağlığı açısından riskli düzeylerin belirlenmesine yönelik olması önemlidir. 


\section{Kurşun, Civa, Kadmiyum: Çocuk Sağlığına Etkileri ve Temasın Belirlenmesinde Saç Örneklerinin Kullanımı}

\section{Kaynaklar}

Agency for Toxic Substances and Disease Registry (ATSDR) 2007. CERCLA Priority List of Hazardous Substances. U.S.Department of Health and Human Services. Atlanta, GA (http://www.atsdr.cdc.gov/cercla/07list.html. (Ulaşılma Tarihi: 20.02.2012).

Agency for Toxic Substances and Disease Registry (ATSDR). 2008. Toxicological Profile for Cadmium. Atlanta, GA: U.S. Department of Health and Human Services, Public Health service (http://www.atsdr.cdc.gov/toxprofiles/tp5.pdf)

Agency for Toxic Substances and Disease Registry (ATSDR) 2001. The Agency for Toxic Substances and Disease Registry, Atlanta, Georgia. Summary report on hair analysis panel discussion exploring the state of the science. http://www.atsdr.cdc.gov/HAC/hair_analysis/hair_analysis.pdf (Ulaşılma tarihi: 12.02.2012)

Agency for Toxic Substances and Disease Registry (ATSDR) 2011. Hair Analysis Panel Discussion: Section: Appendix C, Sharon Seidel. http://www.atsdr.cdc.gov/HAC/hair_analysis/Appendix_c_sharon.html. (erişim tarihi: 13.03.2012).

Afridi,H.I., Kazi, T.G., Brabazon, D., ve Naher, S. 2011. Association between essential trace and toxic elements in scalp hair samples of smokers rheumatoid arthritis subjects. Sci Total Environ. 412-413:93-100.

Ali, M.M., Murthy, R.C., ve Chandra, S.V. 1986. Developmental and long term neurobehavioral toxicity of low level in utero cadmium exposure in rats. Neurobehav Toxicol Teratol. 8:463-468.

Amin-Zaki, L., Majeed, M.A., Elhassani, S.B., Clarkson, T.W., Greenwood, M.R., ve Doherty, R.A. 1979. Prenatal methylmercury poisoning. Clinical observations over five years. Am J Dis Child. 133(2):172-7.

Atabek, M.E., Kurtoglu, S., Pirgon, O., Uzum, K., ve Saraymen, R. 2007. Relation of in utero lead exposure with insulin-like growth factor-I levels and neonatal anthropometric parameters. Int J Hyg Environ Health, 210(1): 91-5.

Baranski, B. 1985. Effect of exposure of pregnant rats to cadmium on prenatal and postnatal development of the young. J Hyg Epidemiol Microbiol Immunol 29:253-262.

Barbosa, Jr.F., Tanus-Santos, J.E., ve Gerlach, R.F. 2005. A Critical Review of Biomarkers Used for Monitoring Human Exposure to Lead: Advantages, Limitations, and Future Needs. Environ Health Pers. 113(12):1669-74.

Barton, H.J. 2011. Advantages of the use of deciduous teeth, hair, and blood analysis for lead and cadmium bio-monitoring in children. A study of 6-year-old children from Krakow (Poland). Biol Trace Elem Res. 143(2):637-58.

Berglund, M., Lind, B., Björnberg, K.A., Palm, B., Einarsson, O., ve Vahter, M. 2005. Inter-individual variations of human mercury exposure biomarkers: a cross-sectional assessment. Environmental Health, 3;4:20.

Bonithon-Kopp, C., Huel, G., Moreau, T., ve Wendling, R. 1986. Prenatal exposure to lead and cadmium and psychomotor development of the child at 6 years. Neurobehav Toxicol Teratol. 8(3):307-10.

Butler, W.J., Houseman, J., Seddon, L., McMullen, E., Tofflemire, K., ve Mills, C. 2006. Maternal and umbilical cord blood levels of mercury, lead, cadmium, and essential trace elements in Arctic Canada. Environ Res, 100(3): 295-318.

Chevrier, C., Sullivan, K., White, R.F., Comtois, C., Cordier, S., ve Grandjean, P. 2009. Qualitative assessment of visuospatial errors in mercury-exposed Amazonian children. Neurotoxicology. 30(1):37-46.

Clarkson, T.W. 1998. Human Toxicology of Mercury. J Trace El Exper Med. 11:303-317.

Cox, C., Clarkson, T.W., Marsh, D.O., Amin-Zaki, L, Tikriti, S., ve Myers, G.G. 1989. Dose-response analysis of infants prenatally exposed to methyl mercury: an application of a single compartment model to single-strand hair analysis. Environ Res. 49(2):318-32.

Davidson, PW., Myers, G.J, ve Weiss, B. 2004. Mercury exposure and child development outcomes. Pediatrics, 113:1023-29.

Dietz, R., Outridge, P.M., ve Hobson, K.A. 2009. Anthropogenic contributions to mercury levels in present-day Arctic animals--a review. Sci Total Environ. 407(24):6120-31.

Díez, S., Delgado, S., Aguilera, I., Astray, J., Pérez-Gómez, B., ve Torrent, M. 2009. Prenatal and early childhood exposure to mercury and methylmercury in Spain, a high-fish-consumer country. Arch Environ Contam Toxicol, 56(3): 615-22.

Esteban, E., Rubin, C.H., Jones, R.J., ve Noonan, G. 1999. Hair and blood as substrates for screening children for lead poisoning. Arch Environ Health. 54:436-440.

Esteban, M., ve Castaño, A. 2009. Non-invasive matrices in human biomonitoring: a review. Environ Int, 35(2):438-49.

Gerhardsson, L., Englyst, V., Lundström, N.G., Nordberg, G., Sandberg, S., ve Steinvall, F. 1995. Lead in tissues of deceased lead smelter workers. J Trace Elem Med Biol. 9(3):136-43. 


\section{E. Örün ve S.S. Yalçın}

Grandjean, P., Weihe, P., Jørgensen, P.J., Clarkson, T., Cernichiari, E., ve Viderø, T. 1992. Impact of maternal seafood diet on fetal exposure to mercury, selenium, and lead. Arch Environ Health. 47(3):185-95.

Grandjean, P., Weihe, P., White, RF., Debes, F., Araki, S., ve Yokoyama, K. 1997. Cognitive deficit in 7-year-old children with prenatal exposure to methylmercury. Neurotoxicol Teratol. 19:417-28.

Holmes, A.S., Blaxill, M,F., ve Haley, B.E. 2003. Reduced levels of mercury in first baby haircuts of autistic children. Int $J$ Toxicol. 22(4):277-85.

Hu, H., Rabinowitz, M., ve Smith, D. 1998. Bone lead as a biological marker in epidemiologic studies of chronic toxicity: conceptual paradigms. Environ Health Perspect. 106(1):1-8.

Huel, G., Everson, R.B., Menger, I. 1984. Increased hair cadmium in newborns of women occupationally exposed to heavy metals. Environ Res. 35(1):115-21.

Järup, L.2003. Hazards of heavy metal contamination. Br Med Bull, 68, 167-82.

Järup, L., ve Akesson, A. 2009. Current status of cadmium as an environmental health problem. Toxicol Appl Pharmacol. $1 ; 238(3): 201-8$.

Markowitz, M. Lead Poisoning In: Kliegman RM, Behrman RE, Jenson HB, Stanton BF. Nelson Textbook of Pediatrics.18 th ed. Saunders 2007( pp: 2913-2917).

Marques, R.C., Garrofe Dórea, J., Rodrigues Bastos, W., de Freitas Rebelo, M., de Freitas Fonseca, M., ve Malm, O. 2007. Maternal mercury exposure and neuro-motor development in breastfed infants from Porto Velho (Amazon), Brazil. Int J Hyg Environ Health. 210(1):51-60.

Mortada, W.I., Sobh, M.A., ve El-Defrawy, M.M. 2004. The exposure to cadmium, lead and mercury from smoking and its impact on renal integrity. Med Sci Monit 10:CR112-116.

Ng, D.K., Chan, C.H., Soo, M.T., ve Lee, R.S. 2007. Low-level chronic mercury exposure in children and adolescents: metaanalysis. Pediatr Int. 49:80-7.

Nowak, B., ve Chmielnicka, J. 2000. Relationship of lead and cadmium to essential elements in hair, teeth and nails of environmentally exposed people. Ecotoxicol and Environ Safety 46;265-274.

Omarova, A., ve Phillips, C.J.C. 2007. A meta-analysis of literature data relating to the relationships between cadmium intake and toxicity in humans. Environ Research 103:432-440.

Omokhodion, F.O., ve Crockford, G.W. 1991. Lead in sweat and its relationship to salivary and urinary levels in normal healthy subjects. Sci Total Environ.103:113-22.

Ozden, T.A., Gökçay, G., Ertem, H.V., Süoğlu, O.D., Kiliç, A., Sökücü, S., ve Saner, G. 2007. Elevated hair levels of cadmium and lead in school children exposed to smoking and in highways near schools. Clin Biochem. 40(1-2):52-6.

Özden, T.A., İşsever, H., Gökçay, G., ve Saner, G. 2003. 0-2 Yaş arası çocuklarda saç Pb düzeyleri ve kronik Pba maruz kalma nedenleri. Ist. Tip Fak. Mecmuası 66:4, 2003.

Patrick, L. 2003. Toxic metals and antioxidants: Part II. The role of antioxidants in arsenic and toxicity. Altern Med Rev. $8(2) ; 112-116$.

Petering, H.G., Choudhury, H., ve Stemmer, K.L. 1979. Some effects of oral ingestion of cadmium on zinc, copper, and iron metabolism. Environ Health Perspect. 28:97-106.

Rabinowitz, M., Leviton, A., ve Needleman, H. 1985. Lead in milk and infant blood: a dose-response model. Arch Environ Health. 40(5):283-6.

Razi, C.H., Akın, K.O., Harmanc1, K., Ozdemir, O., Abacı, A., Hızlı, S., Renda, R., ve Celik, A. 2012. Relationship between hair cadmium levels, indoor ETS exposure and wheezing frequency in children. Allergol Immunopathol (Madr). 40(1):51-9.

Sakamoto, M., Kubota, M., ve Matsumoto, S. 2002. Declining risk of metylmercury exposure to infants during lactation. Environ Res 90:185-189.

Schuhmacher, M., Domingo, J.L., Llobet, J.M., ve Corbella, J. 1991. Lead in children's hair, as related to exposure in Tarragona Province, Spain. Sci Total Environ. 15;104(3):167-73.

Schütz, A., Bergdahl, I.A., Ekholm, A., ve Skerfving, S. 1996. Measurement by ICP-MS of lead in plasma and whole blood of lead workers and controls. Occup Environ Med. 53(11):736-741. 


\section{Kurşun, Civa, Kadmiyum: Çocuk Sağlı̆̆ına Etkileri ve Temasın Belirlenmesinde Saç Örneklerinin Kullanımı}

Seifert, B., Becker, K., Helm, D., Krause, C., Schulz, C., ve Seiwert, M. 2000. The German Environmental Survey 1990/1992 (GerES II): reference concentrations of selected environmental pollutants in blood, urine, hair, house dust, drinking water and indoor air. J Expo Anal Environ Epidemiol. 10(6 Pt 1):552-65.

Serdar, M.A., Akin, B.S., Razi, C., Akin, O., Tokgoz, S., Kenar, L., ve Aykut, O. 2012. The Correlation Between Smoking Status of Family Members and Concentrations of Toxic Trace Elements in the Hair of Children. Biol Trace Elem Res. Feb 10. (Basimda)

Souad, C., Farida, Z., Nadra, L., François, B., Bougle, D., ve Azeddine, S. 2006. Trace element level in infant hair and diet, and in the local environment of the Moroccan city of Marrakech. Sci Total Environ.370(2-3):337-42.

Stellern, J., Marlowe, M., Cossairt, A., ve Errera, J. 1983. Low lead and cadmium levels and childhood visual-perception development. Percept Mot Skills. 56(2):539-44.

Steuerwald, U., Weihe, P., Jørgensen, PJ., Bjerve, K., Brock, J., Heinzow, B., Budtz-Jørgensen, E., ve Grandjean, P. 2000. Maternal seafood diet, methylmercury exposure, and neonatal neurologic function. J Pediatr, 36(5), 599-605.

Takagi, Y., Matsuda, S., Imai, S., Ohmori, Y., Masuda, T., Vinson, J.A., Mehra, M.C., Puri, B.K., ve Kaniewski, A. 1988. Survey of trace elements in human nails: an international comparison. Bull Environ Contam Toxicol. 41(5):690-5.

Thatcher, R.W., Lester, M.L., McAlaster, R., ve Horst, R. 1982. Effects of low levels of cadmium and lead on cognitive functioning in children. Arch Environ Health. 37(3):159-66.

Triche, E.W., ve Hossain, N. 2007 Environmental factors implicated in the causation of adverse pregnancy outcome. Semin Perinatol. 31(4), 240-2.

United State Environmental Protection Agency. (U.S. EPA)(2005). Office of Science and Technology, Office of Water. Water Quality Criterion for the Protection. of Human Health. Methylmercury 2005. http://www.epa.gov/waterscience/criteria/methylmercury/document.html).(ulaşılma tarihi: 23.08.2009)

Viaene, M.K., Masschelein, R., Leenders, J., De Groof, M., Swerts, L.J., ve Roels, H.A. 2000. Neurobehavioural effects of occupational exposure to cadmium: a cross sectional epidemiological study. Occup Environ Med. 57(1):19-27.

Wilhelm, M., Ohnesorge, F.K., ve Hötzel, D. 1990. Cadmium, copper, lead, and zinc concentrations in human scalp and pubic hair. Sci Total Environ. 1990 92:199-206.

Wong, SL., ve Lye, E.J. 2008. Lead, mercury and cadmium levels in Canadians. Health Rep, 19(4), 31-6.

World Health Organization (WHO) Regional Office for Europe. 2000. Mercury Air Quality Guidelines. Second Ed. Chapter 6.9, 1-15. Copenhagen,Denmark.(http://www.euro.who.int/document/aiq/6 9mercury.pdf) (Ulaş1ma tarihi: 20.02.2012).

World Health Organization (WHO) Regional Office for Europe. 2001. Lead Air Quality Guidelines. Second Ed. Chapter 6.7, 1-17. Copenhagen, Denmark (http://www.euro.who.int/document/aiq/6_7lead.pdf). (Ulaşım Tarihi:20.02.2012).

World Health Organization (WHO) Regional Office for Europe. 2007 European Environment and Health Information System (ENHIS). Exposure of children to chemical hazards in food. Fact sheet no: 4.4. (http://www.enhis.org/object_document/o4736n27387.html) (ulaş1lma tarihi: 20.02.2012).

World Health Organization (WHO) 2006. Environmental Health Criteria, 234. Elemental Speciation in Health Risk Assessment. Geneva. (http://www.who.int/ipcs/publications/ehc/ehc234.pdf). (ulaşılma tarihi:20.03.2012). 